\title{
Pathophysiology of Cystic Fibrosis
}

\author{
Scott H. Donaldson Richard C. Boucher \\ Cystic Fibrosis Research and Treatment Center, University of North Carolina at Chapel Hill, Chapel Hill, N.C., USA
}

\section{Key Words}

Cystic fibrosis $\cdot$ CFTR $\cdot$ Epithelial sodium channel $\cdot$ Mucus

clearance $\cdot$ Ion transport · Airway surface liquid

\begin{abstract}
Understanding the development of lung disease in cystic fibrosis (CF) has been a sought after goal for several decades. With the cloning of the CF transmembrane conductance regulator (CFTR) gene and other advances in the study of airway epithelial biology, a much clearer picture of disease pathophysiology has emerged. Our best available evidence points to dysregulated ion transport as the underlying defect that causes depletion of airway surface liquid volume, i.e. dehydration, and an associated impairment in mucus clearance. Mucostasis in turn predisposes the CF lung to bacterial infection, which rapidly becomes chronic due to the nature of the CF secretions themselves. The nonresolving neutrophilic inflammatory response to this chronic infection in turn causes progressive and permanent airway damage, such that bronchiectasis and respiratory failure are the common findings in end-stage CF lung disease. Hopes of preventing this cascade of events are provided by the development of new therapies that address the underlying defect of airway dehydration.
\end{abstract}

Copyright @ 2006 Nestec Ltd., Vevey/S. Karger AG, Basel

\section{Introduction}

Cystic fibrosis (CF) is the most common lethal genetic disease in Caucasian populations. Mutations in the $\mathrm{CF}$ transmembrane conductance regulator (CFTR) gene, which is located on the long arm of chromosome 7, confer disease in an autosomal recessive fashion. To date, more than 1,400 individual mutations have been identified and reported in the Cystic Fibrosis Mutation Database (http://www.genet.sickkids.on.ca/cftr/), making population screening solely via genetic techniques impractical. The $\Delta$ F508 mutant allele, which encodes a single amino acid deletion within this 1,480-amino-acid-long protein, is by far the most prevalent allele, accounting for $66 \%$ of mutations worldwide [1]. The classical CF phenotype is quite complex, involving multiple epithelial lined organs [De Boeck, pp. 124-126], although lung manifestations are the dominant source of morbidity and mortality. Significant progress has been made in recent years toward a clearer understanding of the pathway that links CFTR gene mutations to clinical manifestations of $\mathrm{CF}$ and, in particular, the mechanisms that underlie the apparent failure of lung defense. In this review, we will focus on the pathophysiologic mechanisms that make the CF lung vulnerable to the development of chronic bacterial infections and the subsequent events that produce progressive bronchiectatic lung disease.

\section{KARGER}

Fax +4161306 1234

E-Mail karger@karger.ch

www.karger.com
(C) 2006 Nestec Ltd., Vevey/S. Karger AG, Basel

0517-8606/06/0643-0101\$23.50/0

Accessible online at:

www.karger.com/ane
Scott H. Donaldson, MD

6019 Thurston Bowles Building, CB\# 7248

University of North Carolina at Chapel Hill

Chapel Hill, NC 27599 (USA)

Tel. +1 919966 9198, Fax +1919966 5178, E-Mail Scott_Donaldson@med.unc.edu 


\section{CFTR Is a Regulator of Epithelial Salt and Water Transport}

The earliest notion that CF results from abnormal electrolyte transport came from observations that $\mathrm{CF}$ sweat contains elevated sodium and chloride concentrations $[2,3]$. Further evidence came from multiple studies that demonstrated abnormal ion transport across other affected organs, including airways [4], pancreatic ducts [5], biliary ducts [6,7], and the colon [8]. The cloning of the CFTR gene $[9,10]$ and its subsequent identification as a chloride channel $[11,12]$ were breakthrough events that further solidified the link between dysregulated ion transport and the various organ level manifestations of CF. The role of CFTR in epithelial physiology, however, has now been shown to extend beyond its function as a $\mathrm{Cl}^{-}$channel as many studies have demonstrated that CFTR is involved in the regulation of other ion channels. Most notably, CFTR exerts an inhibitory effect on the epithelial sodium channel $(\mathrm{ENaC})[13,14]$, via an as of yet undetermined mechanism, while also influencing the activity of other distinct chloride channels $[15,16]$. CFTR, therefore, is positioned as a central regulator of salt and water transport across multiple epithelia, and its absence results in organ-specific ion transport abnormalities. As a consequence, reduced net fluid secretion across affected epithelia is a common theme that leads to ductal (pancreatic, biliary, bronchiolar, vas deferens) obstruction and subsequent organ dysfunction (exocrine pancreatic insufficiency, cirrhosis, bronchiectasis, male infertility).

\section{Pathophysiology of CF Lung Disease}

CF lung disease is distinct from other organ system manifestations in CF because (1) lung disease is the cause of premature death in about $95 \%$ of patients, and (2) only the lung develops a chronic infection phenotype with an associated intense inflammatory response. Further discussion of the pathophysiologic processes that contribute to CF lung disease is therefore warranted.

Current evidence suggests that the CF lung is free of infection and not inflamed at the time of birth $[17,18]$. Over the course of months to years, however, stigmata of first recurrent and then chronic infection begin to appear. Microbiologic studies reveal a fairly typical evolution of pathogens, with respiratory viruses, Haemophilus influenzae and Staphylococcus aureus, predominating early in life. With time, more problematic and in- creasingly resistant pathogens, including Pseudomonas aeruginosa and other Gram-negative bacteria (e.g. Burkholderia cepacia complex, Stenotrophomonas maltophilia, Achromobacter xylosoxidans), often dominate the clinical picture. Direct tests of systemic immunity, which are normal, and the absence of an infectious phenotype outside the respiratory tract suggest that a local defect in lung defense is responsible for the development of CF lung disease. In fact, the intense neutrophilic inflammatory response to airway infections is arguably more robust and persistent than in non-CF conditions [19-22], yet the CF lung ultimately fails to clear bacterial pathogens once they become established. It is this defect in innate airways defense that has been the focus of intense investigation and the recent target for therapies aimed at preventing or slowing the cascade of pathogenic events that culminate in progressive lung destruction.

\section{Innate Defense Mechanisms in the Normal Lung}

Because the lung is continuously exposed to both noxious and infectious agents, a multitiered defense has evolved that is able to continuously cleanse airways without inciting a potentially harmful inflammatory response. The mucus clearance (MC) system appears to be paramount for airways defense and is the locus of defects that lead to genetic lung diseases such as CF and primary ciliary dyskinesia. Other important elements in this defense system include locally residing leukocytes (e.g. alveolar and airway macrophages), mucosal immunoglobulins and secreted antimicrobial compounds (e.g. lysozyme, lactoferrin), all of which are available to neutralize microbes that escape the first line of defense, i.e., mechanical MC.

A normally functioning $\mathrm{MC}$ apparatus requires the coordinated activities of mucus secretion, salt and water transport, and cilial beating. Mucus secretion creates a protective blanket that efficiently binds inhaled particles via its panoply of carbohydrate epitopes, where they become entrapped via turbulent flow. The mucus layer, which floats on top of a less viscous and physically distinct liquid layer, is propelled cephalad by a combination of coordinated cilia beating and airflow/cough. The underlying liquid layer, often referred to as the 'sol' or 'periciliary liquid' layer (PCL), is itself quite complex and specially structured to provide a low resistance environment for cilial beating while allowing efficient mechanical coupling between the tips of cilia and the mucus layer. 
Active ion transport creates the driving force for regulated liquid absorption and secretion [23], which in turn maintains an appropriate PCL height (approximating the height of an outstretched cilium) and adequate hydration of the mucus layer [24]. Perhaps most importantly, the PCL may also function as a lubricant that prevents adhesion between the mucus layer and cell surfaces, thusfacilitatingbothcilia-drivenand cough-dependent MC [25].

\section{The Innate Host Defense Defect in CF}

A number of hypotheses have been raised to explain the combination of excessive airway mucus, typical bacterial infections (especially $P$. aeruginosa), and intense neutrophilic inflammation that is characteristic of CF lung disease. Both increased bacterial binding in CF airways - due to altered glycosylation of luminal proteins [26-28] - and reduced CFTR-mediated binding, internalization and clearance of Pseudomonas $[29,30]$ - have been proposed to predispose CF patients to chronic airway infections. Neither explanation appears adequate, however, to explain the whole of CF lung disease. In the case of the 'altered glycosylation' hypothesis, infection in patients with genotypes other than $\Delta \mathrm{F} 508 / \Delta \mathrm{F} 508$ is not explained [31]. In the latter hypothesis, where CFTR is proposed to act as a Pseudomonas receptor, the onset of clinically apparent lung disease prior to acquisition of $P$. aeruginosa infection is not explained. Further, patients with CFTR mutations that lead to expression of channels at the apical membrane (i.e. 'class IV' mutations) also have an infectious phenotype, despite the presence of a poorly conducting but otherwise intact CFTR channel.

Alternative explanations for the unusual predisposition to lung infections in CF have centered on the hypothesis that CF airway secretions themselves are abnormal in composition. Earlier studies reported that CF airway surface liquid (ASL) was relatively hypertonic (vs. normal ASL) and, as a result, a poor environment for the function of salt-sensitive antimicrobials (defensins) [32, 33]. These studies, however, have largely been discounted as the result of careful studies that uniformly demonstrate ASL isotonicity (normal and CF) [3438] and that the dominant antimicrobial molecules (e.g. lactoferrin, lysozyme) are intact in CF [39]. An additional 'compositional' hypothesis raised to explain impaired host defense in CF relates to the loss of bicarbonate secretion through CFTR. Although some studies in- dicate that the $\mathrm{pH}$ of airway surface secretions may be lower in CF [40-42], the precise mechanism(s) by which this phenomenon may lead to airway infection is not clear.

In contrast to these 'cell biological' and 'ASL compositional' hypotheses, the currently favored 'low ASL volume' hypothesis directly relates the previously described ion transport abnormalities to impairment of MC. In CF airway epithelia, two CFTR functions are lost. First, the CFTR-mediated inhibitory influence over $\mathrm{ENaC}$ is absent. As a result, sodium absorption proceeds unchecked regardless of the status of the ASL volume. Second, the capacity to initiate $\mathrm{Cl}^{-}$secretion via CFTR in response to ASL volume depletion is lost. Therefore, whereas a normal airway epithelia blends sodium absorption and chloride secretion in response to adenosine concentrations on airway surfaces (via $A_{2 b}$ receptors that bind adenosine and regulate cAMP levels) in order to regulate the amount of fluid on airway surfaces [43], CF epithelia fail to do so effectively [44]. Instead, because airway epithelia are water permeable, the combination of sodium hyperabsorption and inadequate chloride secretion produces a reduced volume of isotonic ASL. With volume depletion, the PCL becomes too shallow to permit normal cilial motion and clearance via this mechanism is lost (fig. 1). Further, depletion of the PCL may allow contact between the overlying mucus layer and cell surfaces, allowing the development of adhesive interactions between cell surface (tethered) mucins and secreted mucus components. As a result, both cilia-dependent and cough-dependent MC is impaired. Finally, dehydration of the mucus layer increases its viscoelasticity, thereby reducing its transportability. The concentration of mucins within the mucus layer also tightens the mesh through which recruited neutrophils must migrate to reach intraluminal bacteria, causing an additional defect in host defense [45]. This series of events, therefore, constitutes the pathophysiologic basis of disease initiation in CF and results in mucus stasis and the formation of adherent mucus plaques on airway surfaces. It is these plaques that provide the environment in which specific bacteria are able to persist and cause chronic suppurative lung disease (fig. 2).

Given the importance of $\mathrm{MC}$ for lung defense, it is not surprising that a redundant fluid-secreting pathway is present in airways - namely calcium-activated chloride channels (CACC), which are activated by the binding of adenosine $5^{\prime}$-triphosphate (ATP) to $\mathrm{P}_{2} \mathrm{Y}_{2}$ receptors. ATP is released from epithelial cells, most notably in response to physical stimuli, such as the mild shear stress that is 


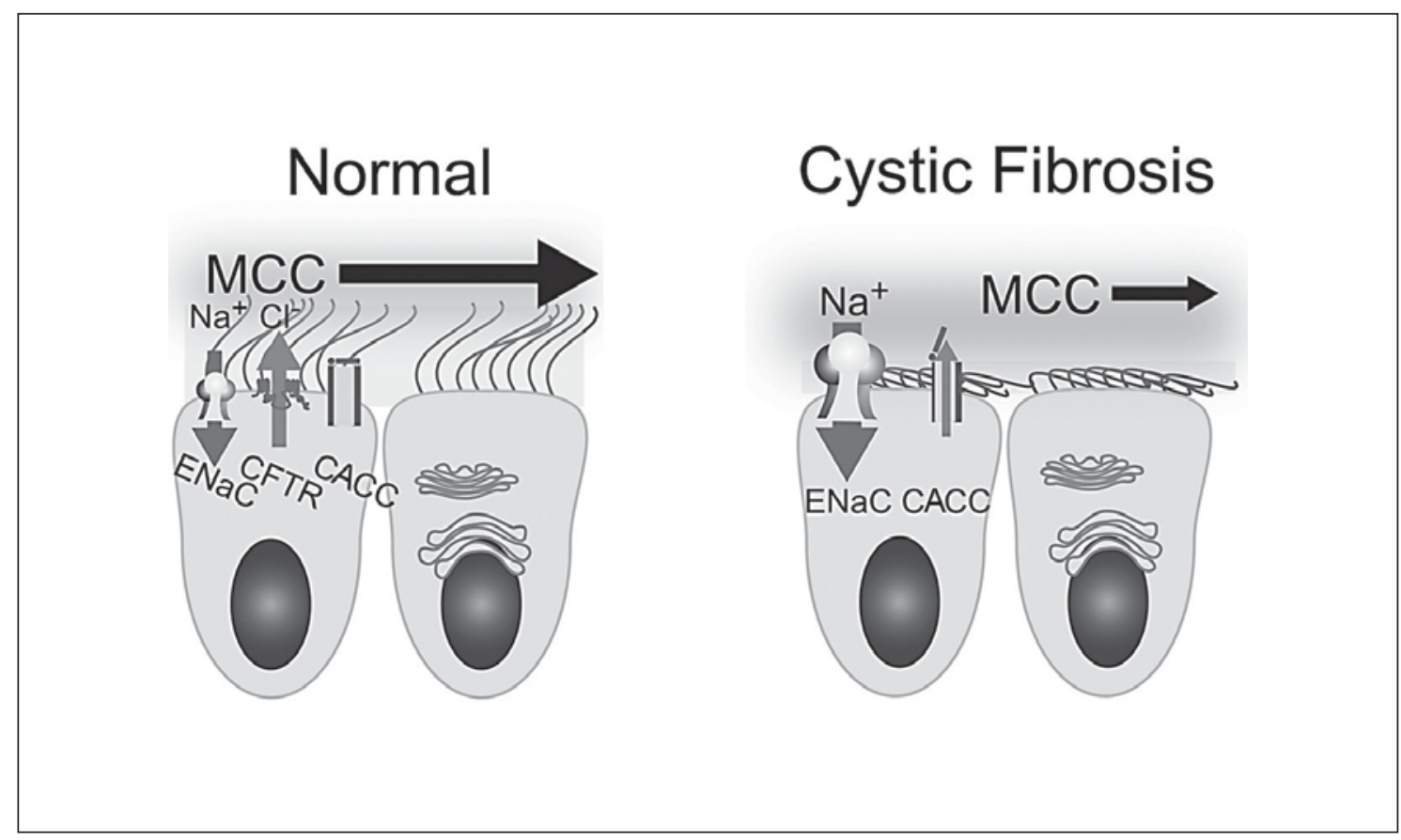

Fig. 1. Normal airway epithelial cells regulate sodium (via ENaC) and chloride (via CFTR and CACC) transport in order to maintain an optimal periciliary liquid layer height in order to support cilial motion and to adequately hydrate the overlying mucus layer. As a result, MCC is maintained. CF epithelia are missing CFTR-mediated chloride transport and hyperabsorb sodium (via ENaC). Despite partial compensation by chloride secretion through CACC, depletion of the PCL layer and mucus dehydration ensues, and MCC is slowed as the result.

imparted by airflow during tidal respiration and cough [44]. Recent studies suggest that this system is functional in $\mathrm{CF}$ airways and can provide sufficient, but less than normal, airway surface hydration for MC [44]. However, sole reliance on this mechanism for maintaining ASL volume in CF becomes particularly problematic when insults (e.g. viral infection) perturb the carefully regulated ATP-signaling pathway. Increased expression of enzymes that hydrolyze ATP occurs in response to various inflammatory stimuli [46] and, in the case of experimental respiratory syncytial virus infection, was shown to reduce ATP levels and cause ASL volume depletion [44] (fig. 3). It is postulated, therefore, that episodic insults to the $\mathrm{CF}$ airway cause decompensation of the ASL volume regulation system and result in regional impairment of MC. It is further postulated that 'exacerbations' of CF lung disease may be the clinical expression of these episodic events. Over time, these insults may create a self-perpetuating cycle of reduced clearance and chronic bacterial infection, thus explaining the observed chronic progression of CF lung disease.
Evidence for the validity of the 'low volume' hypothesis is provided by multiple in vitro model systems, as well as in vivo measurements, that have validated the predictions that ASL is isotonic [34,37,47], that the PCL is depleted in CF relative to normal epithelia [24,34], and that mucus stasis and adhesion occur as the result of PCL volume depletion [34]. In addition, the nasal septal mucosa of the CFTR knockout mouse, which is the only airway region that demonstrates the typical CF ion transport phenotype, develops a local CF-like phenotype with reduced ASL height and evidence of spontaneous infection/inflammation [24]. More recently, a transgenic mouse that overexpresses the $\beta$ subunit of $\mathrm{ENaC}$ was created to better model the volume hyperabsorption that is observed in human CF airways. The result was an animal with a striking CF-like phenotype, including (1) demonstrable sodium hyperabsorption across airways, (2) ASL volume depletion, (3) mucus hypersecretion and adhesion to airways, (4) 'spontaneous' (i.e., not requiring experimental inoculation with an infectious agent) inflammation, and (5) slowed bacterial clearance [48]. 


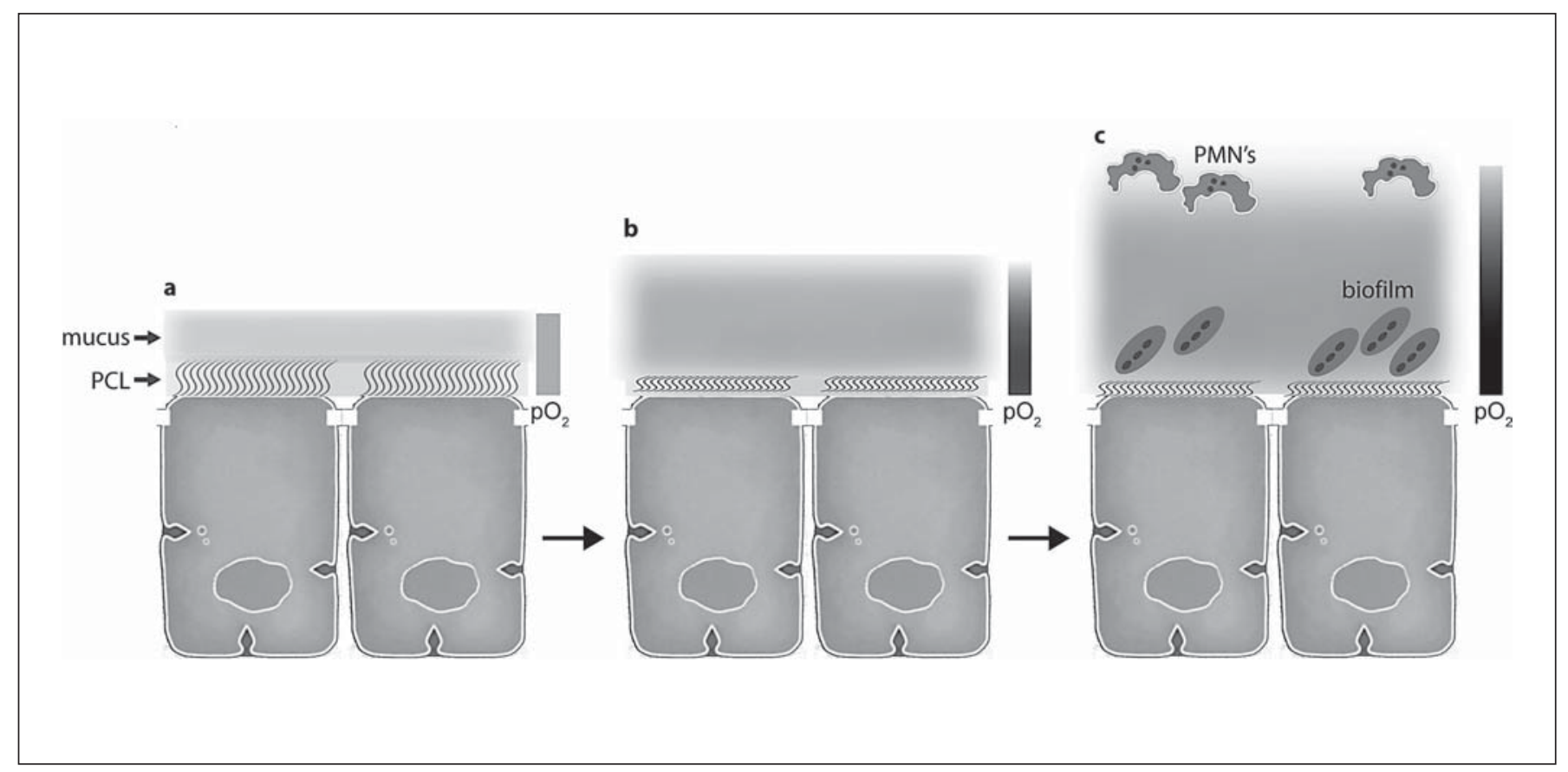

Fig. 2. a The normal lung maintains a PCL layer that approximates the height of an outstretched cilium, normally hydrates the mucus layer, and airway surface secretions are aerobic. b Early in CF lung disease, ion transport abnormalities result in depletion of the PCL layer, preventing normal cilial motion and causing the thickening mucus layer to begin to impinge upon cilia. c With advanced CF lung disease, a markedly dehydrated and anaerobic mucus mass accumulates in the airway lumen, becomes adherent to airway surface due to loss of the PCL layer, and supports the growth of Pseudomonas microcolonies in a biofilm structure. Recruited neutrophils are unable to penetrate the thickened mucus layer and therefore do not reach bacteria within the mucus plug.

In vivo measurements of mucociliary clearance (MCC) in CF patients provide interesting additional insights into the pathophysiology of CF lung disease and provide a test of the reduced MC hypothesis. The largest data set describing MCC in CF is that of Robinson et al. [49], which suggested that MCC is routinely abnormal in CF patients, including those with normal spirometric values. This observation suggests that MC is indeed an early, likely primary, CF defect rather than a secondary result of lung disease. In contrast, more recently reported data from Donaldson et al. [50] suggested that MCC in the large airways of CF subjects was not different from normal, whereas clearance defects were detected in measures that reflect small airway clearance (i.e. peripheral lung clearance and 24-hour clearance measurements). In addition, this study demonstrated that cough-mediated clearance was negligible from peripheral airways in CF. These data, therefore, lend further support to the notion that $\mathrm{MC}$ is abnormal in $\mathrm{CF}$, but that the defect may be heterogeneous and most pronounced in the small airway regions where $\mathrm{CF}$ lung disease is thought to originate.

\section{The Progression of CF Lung Disease - Beyond ASL Dehydration}

With dehydration of airway surfaces in CF and the formation of mucus plaques, the stage is set for the development of chronic bacterial infection and the resulting inflammatory response that ensues. The plaques themselves, being stagnant and relatively impenetrable to neutrophils, create an ideal niche for bacteria that are either inhaled or aspirated from the oropharynx. As mucus accumulates in these plaques, a frank plug may develop and cause airway obstruction, further encouraging the establishment of bacterial infection. Importantly, a local anaerobic niche of macroscopic mucus plaques and plugs is 


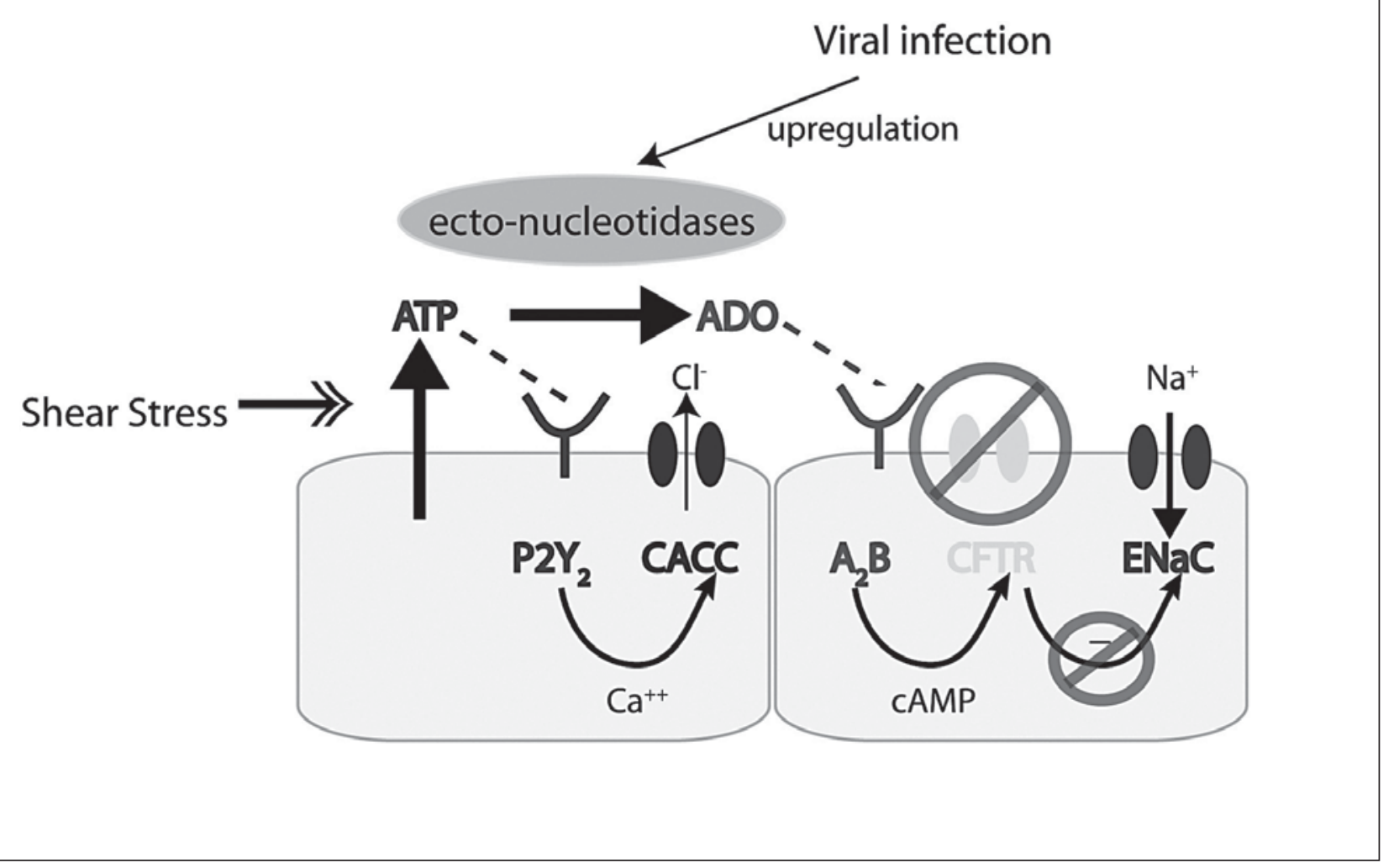

Fig. 3. CF epithelia rely upon ATP-mediated chloride secretion for ASL formation. Shear stress, induced by airflow over airway surfaces, leads to the release of ATP, which binds to $\mathrm{P}_{2} \mathrm{Y}_{2}$ receptors and stimulates chloride secretion via CACC. Ectonucleotidases degrade released ATP, limiting its effect. In the setting of viral infection or other inflammatory stimuli, ectonucleotidases are upregulated, ATP metabolism is increased, and the ability to secrete chloride and water (via CACC) is impaired in the CF airway. Of note, the formation of adenosine does not stimulate chloride/water secretion in the CF airway because of the absence of CFTR. $A_{2} B=A_{2} B$ adenosine receptor; $\mathrm{ADO}=$ adenosine.

created as a consequence of both a long $\mathrm{O}_{2}$ diffusion distance and elevated rates of $\mathrm{O}_{2}$ consumption by the $\mathrm{CF}$ epithelium, as demonstrated by both in vitro and in vivo (bronchoscopic) studies [51]. This microenvironment is believed to select for pathogens best adapted to it, including Pseudomonas, thus explaining the observation that $\mathrm{CF}$, and to a somewhat lesser extent other forms of bronchiectasis, is afflicted by a relatively small but unique cadre of typical pathogens. Of note, the complexity of the bacterial communities that develop in this environment is likely to be dramatically underestimated using routine microbiologic techniques. More recently, molecular techniques have documented far greater bacterial diversity in the CF lung than previously realized, including the presence of organisms that require anaerobic conditions for growth [52].

New information regarding the behavior of Pseudomonas in the CF lung has been very helpful in understanding the pathophysiology of CF while also bringing hope for new therapeutic targets. In its natural environment, Pseudomonas is a mobile, planktonic bacterium. In the CF lung, pseudomonads drastically alter their gene expression, at least in part due to quorum-sensing signals, such that a stationary bacterial microcolony, or biofilm, develops within mucus plaques/plugs. The production of alginate, conversion to anaerobic metabo- 
lism, as well as the concentrated mucin environment itself, all contribute to evasion of immune defenses and antibiotic interventions, and result in bacterial persistence in the CF lung. The ineffective inflammatory response that follows, rather than clearing infection, instead causes progressive airway damage and bronchiectasis.

\section{Therapeutic Implications}

Studies that address the pathogenesis of CF lung disease have not only furthered our understanding of this complex process, but have also uncovered new therapeutic targets for drug development. Clearly, the treatment standards of physical airway clearance and antibiotics are logical means of minimizing the mass of retained mucus and airway obstruction while also reducing the burden of infecting organisms that stimulates further inflammation and mucus production. However, it is now apparent that interventions that restore the normal hydration status of the PCL and mucus layers prior to the development of mucus adhesion have the potential to greatly slow the initiation and progression of CF lung disease. Towards that end, inhaled hypertonic saline solutions that osmotically draw water into the ASL layer are now being used clinically. This approach represents the first generation of therapies actually aimed at the underlying defect in CF. Gratifyingly, this simple approach to therapy has been shown to improve MCC and spirometry while also lessening symptoms and, most importantly, the frequency of disease exacerbations [50, 53; Strandvik, p. 136].

Currently in development are other agents that address ASL volume depletion via other mechanisms of action. For example, both long-acting $\mathrm{P}_{2} \mathrm{Y}_{2}$ agonists (which stimulate chloride secretion via CACC) and $\mathrm{ENaC}$ inhibitors are in clinical trials and have the potential to rebalance liquid secretion/absorption across $\mathrm{CF}$ airways using the ion transport apparatus that is immediately available. Alternatively, intense efforts using high-throughput screening of chemical libraries are beginning to identify agents that improve the cellular processing and function of the most common mutant CFTR channel (i.e. $\Delta$ F508), such that it may reach the apical plasma membrane and function as a chloride channel [54]. It is likely that early and consistent use - i.e. in infancy or prior to onset of significant lung disease - of any therapy that effectively addresses ASL volume depletion will be necessary. However, this strat- egy now for the first time provides the opportunity to intervene in a preventative, rather than reactive fashion, and thereby significantly alters the course of this lethal lung disease. Clinical trials that test this approach to therapy in the youngest of patients should be forthcoming soon.

\section{Conclusion}

Although a number of hypotheses have been proposed that pertain to the origin of CF lung disease, a growing body of evidence suggests that ASL volume depletion with adhesion of thickened mucus to airway surfaces initiates the complex cascade of events that culminate in chronic infection, bronchiectasis, and respiratory failure. These data provide an impetus to target early pathogenic steps with agents that increase ASL volume and detach adherent mucus plaques. Additionally, strategies that target Pseudomonas adapted to an anaerobic environment and biofilm growth may provide improved treatments for patients who already have established lung disease with persistent bacterial infection. Ultimately, however, the application of long-acting therapies that effectively restore the hydration of airway surfaces prior to the development of chronic disease may be needed to greatly reduce the toll this disease has on sufferers with CF. 


\section{References}

1 Tsui LC: Cystic fibrosis mutation database. http://www.genet.sickkids.on.ca/cftr/.

$\checkmark 2$ di Sant' Agnese PA, Darling RC, Perera GA: Abnormal electrolyte composition of sweat in cystic fibrosis of the pancreas. Pediatrics 1953;12:549-563.

3 Quinton PM: chloride impermeability in cystic fibrosis. Nature 1983;301:421-422.

4 Knowles MR, Stutts MJ, Spock A, et al: Abnormal ion permeation through cystic fibrosis respiratory epithelium. Science 1983;221: 1067-1070.

5 Kopelman H, Durie P, Gaskin K, et al: Pancreatic fluid secretion and protein hyperconcentration in cystic fibrosis. N Engl J Med 1985;312:329-334.

-6 Fitz JG, Basavappa S, McGill J, et al: Regulation of membrane chloride currents in rat bile duct epithelial cells. J Clin Invest 1993; 91:319-328.

7 Cohn JA, Strong TV, Picciotto MR, et al: Localization of the cystic fibrosis transmembrane conductance regulator in human bile duct epithelial cells. Gastroenterology 1993; 105:1857-1864.

8 Gowen CW Jr, Gowen MA, Knowles MR: Colonic transepithelial potential difference in infants with cystic fibrosis. J Pediatr 1991; 118:412-415.

-9 Riordan JR, Rommens JM, Kerem B, et al: identification of the cystic fibrosis gene: cloning and characterization of complementary DNA. Science 1989;245:1066-1073.

$\checkmark 10$ Rommens JM, Iannuzzi MC, Kerem B, et al: Identification of the cystic fibrosis gene: chromosome walking and jumping. Science 1989;245:1059-1065.

-11 Bear CE, Li CH, Kartner N, et al: Purification and functional reconstitution of the cystic fibrosis transmembrane conductance regulator (CFTR). Cell 1992;68:809-818.

12 Kartner N, Hanrahan JW, Jensen TJ, et al: expression of the cystic fibrosis gene in nonepithelial invertebrate cells produces a regulated anion conductance. Cell 1991;64:681691.

-13 Stutts MJ, Rossier BC, Boucher RC: Cystic fibrosis transmembrane conductance regulator inverts protein kinase A-mediated regulation of epithelial sodium channel single channel kinetics. J Biol Chem 1997;272: 14037-14040.

-14 Stutts MJ, Canessa CM, Olsen JC, et al: CFTR as a CAMP-dependent regulator of sodium channels. Science 1995;269:847-850.

15 Tarran R, Loewen ME, Paradiso AM, et al: Regulation of murine airway surface liquid volume by CFTR and $\mathrm{Ca}^{2+}$-activated $\mathrm{Cl}^{-}$ conductances. J Gen Physiol 2002;120:407418.
Schwiebert EM, Egan ME, Hwang TH, et al: CFTR regulates outwardly rectifying chloride channels through an autocrine mechanism involving ATP. Cell 1995;81:10631073.

17 Armstrong DS, Grimwood K, Carlin JB, et al: Lower airway inflammation in infants and young children with cystic fibrosis. Am J Respir Crit Care Med 1997;156:1197-1204.

18 Dakin CJ, Numa AH, Wang H, et al: Inflammation, infection, and pulmonary function in infants and young children with cystic fibrosis. Am J Respir Crit Care Med 2002;165: 904-910.

19 Noah TL, Black HR, Cheng PW, et al: Nasal and bronchoalveolar lavage fluid cytokines in early cystic fibrosis. J Infect Dis 1997; 175: 638-647.

20 Muhlebach MS, Stewart PW, Leigh MW, Noah TL: Quantitation of inflammatory responses to bacteria in young cystic fibrosis and control patients. Am J Respir Crit Care Med 1999;160:186-191.

21 Khan TZ, Wagener JS, Bost T, et al: Early pulmonary inflammation in infants with cystic fibrosis. Am J Respir Crit Care Med 1995; 151:1075-1082.

22 Bonfield TL, Konstan MW, Berger M: Altered respiratory epithelial cell cy tokine production in cystic fibrosis. J Allergy Clin Immunol 1999;104:72-78.

23 Tarran R, Grubb BR, Gatzy JT, et al: The relative roles of passive surface forces and active ion transport in the modulation of airway surface liquid volume and composition. J Gen Physiol 2001;118:223-236.

-24 Tarran R, Grubb BR, Parsons D, et al: The CF salt controversy: in vivo observations and therapeutic approaches. Mol Cell 2001;8: 149-158.

25 Raviv U, Giasson S, Kampf N, et al: Lubrication by charged polymers. Nature 2003;425 163-165.

26 Rhim AD, Stoykova L, Glick MC, Scanlin TF: Terminal glycosylation in cystic fibrosis (CF): a review emphasizing the airway epithelial cell. Glycoconj J 2001;18:649-659.

27 Scanlin TF, Glick MC: Terminal glycosylation in cystic fibrosis. Biochim Biophys Acta 1999;1455:241-253.

28 Bryan R, Kube D, Perez A, et al: Overproduction of the CFTR R domain leads to increased levels of asialoGM1 and increased Pseudomonas aeruginosa binding by epithelial cells. Am Respir Cell Mol Biol 1998;19:269-277.

29 Pier GB, Grout M, Zaidi TS, et al: Role of mutant CFTR in hypersusceptibility of cystic fibrosis patients to lung infections. Science 1996;271:64-67.

- 30 Schroeder TH, Reiniger N, Meluleni G, et al: Transgenic cystic fibrosis mice exhibit reduced early clearance of pseudomonas aeruginosa from the respiratory tract. J Immunol 2001;166:7410-7418.
Zar H, Saiman L, Quittell L, Prince A: Binding of Pseudomonas aeruginosa to respiratory epithelial cells from patients with various mutations in the cystic fibrosis transmembrane regulator. J Pediatr 1995; 126:230-233.

32 Smith JJ, Travis SM, Greenberg EP, Welsh MJ: Cystic fibrosis airway epithelia fail to kill bacteria because of abnormal airway surface fluid. Cell 1996;85:229-236.

33 Goldman MJ, Anderson GM, Stolzenberg ED, et al: Human beta-defensin-1 is a saltsensitive antibiotic in lung that is inactivated in cystic fibrosis. Cell 1997;88:553-560.

34 Matsui H, Grubb BR, Tarran R, et al: Evidence for periciliary liquid layer depletion, not abnormal ion composition, in the pathogenesis of cystic fibrosis airways disease. Cell 1998;95:1005-1015.

35 Grubb BR, Chadburn JL, Boucher RC: In vivo microdialysis for determination of nasal liquid ion composition. Am J Physiol Cell Physiol 2002;282:C1423-C1431.

36 Knowles MR, Robinson JM, Wood RE, et al: Ion composition of airway surface liquid of patients with cystic fibrosis as compared with normal and disease-control subjects. J Clin Invest 1997;100:2588-2595.

37 Jayaraman S, Song YL, Vetrivel L, et al: Noninvasive in vivo fluorescence measurement of airway-surface liquid depth, salt concentration, and pH. J Clin Invest 2001;107:317324.

38 Caldwell RA, Grubb BR, Tarran R, et al: In vivo airway surface liquid $\mathrm{Cl}$ - analysis with solid-state electrodes. J Gen Physiol 2002; 119:3-14.

39 Travis SM, Conway BA, Zabner J, et al: Activity of abundant antimicrobials of the human airway. Am J Respir Cell Mol Biol 1999; 20:872-879.

40 Tate S, MacGregor G, Davis M, et al: Airways in cystic fibrosis are acidified: detection by exhaled breath condensate. Thorax 2002;57: 926-929.

41 Song Y, Salinas D, Nielson DW, Verkman AS: Hyperacidity of secreted fluid from submucosal glands in early cystic fibrosis. Am J Physiol Cell Physiol 2006;290:C741-C749.

-42 Coakley RD, Grubb BR, Paradiso AM, et al: Abnormal surface liquid $\mathrm{pH}$ regulation by cultured cystic fibrosis bronchial epithelium. Proc Natl Acad Sci USA 2003;100: 16083-16088.

43 Lazarowski ER, Tarran R, Grubb BR, Van Heusden CA, et al: Nucleotide release provides a mechanism for airway surface liquid homeostasis. J Biol Chem 2004;279:3685536864.

44 Tarran R, Button B, Picher M, et al: Normal and cystic fibrosis airway surface liquid homeostasis: the effects of phasic shear stress and viral infections. J Biol Chem 2005;280: 35751-35759. 
45 Matsui H, Verghese MW, Kesimer M, et al: Reduced three-dimensional motility in dehydrated airway mucus prevents neutrophil capture and killing bacteria on airway epithelial surfaces. J Immunol 2005;175:10901099.

-46 Picher M, Burch LH, Boucher RC: Metabolism of $\mathrm{P} 2$ receptor agonists in human airways: implications for mucociliary clearance and cystic fibrosis. J Biol Chem 2004;279: 20234-20241.

47 Jayaraman S, Song YL, Verkman AS: Airway surface liquid osmolality measured using fluorophore-encapsulated liposomes. J Gen Physiol 2001;117:423-430.
48 Mall M, Grubb BR, Harkema JR, et al: Increased airway epithelial $\mathrm{Na}^{+}$absorption produces cystic fibrosis-like lung disease in mice. Nat Med 2004;10:487-493.

49 Robinson M, Eberl S, Tomlinson C, et al: Regional mucociliary clearance in patients with cystic fibrosis. J Aerosol Med 2000;13: 73-86.

50 Donaldson SH, Bennett WD, Zeman KL, et al: Mucus clearance and lung function in cystic fibrosis with hypertonic saline. N Engl J Med 2006;354:241-250.

51 Worlitzsch D, Tarran R, Ulrich M, et al: Effects of reduced mucus oxygen concentration in airway pseudomonas infections of cystic fibrosis patients. J Clin Invest 2002; 109:317-325.
52 Rogers GB, Carroll MP, Serisier DJ, et al: Characterization of bacterial community diversity in cystic fibrosis lung infections by use of 16s ribosomal DNA terminal restriction fragment length polymorphism profiling. J Clin Microbiol 2004;42:5176-5183.

53 Elkins MR, Robinson M, Rose BR, et al: A controlled trial of long-term inhaled hypertonic saline in patients with cystic fibrosis. $\mathrm{N}$ Engl J Med 2006;354:229-240.

54 Pedemonte N, Lukacs GL, Du K, et al: Smallmolecule correctors of defective deltaF508CFTR cellular processing identified by highthroughput screening. J Clin Invest 2005; 115:2564-2571. 